\title{
Shalat Wajib dan Shalat Sunnah
}

\author{
Penulis: Komala (191370027)
}

\author{
Jurusan Ilmu Hadist Fakultas Ushuluddin dan Adab \\ Universitas Islam Negeri Sultan Maulana Hasanuddin Banten
}

kkomala979@gmail.com 


\section{PENDAHULUAN}

Dalam kehidupan umat islam masyarakat meyakini dan mengetahui bahwa shalat merupakan perintah yang harus di lakukan atau di anjurkan oleh ummat islam itu sendiri. Didalam pelaksanaan sholat ada beberapa hal yang harus di lakukan seseorang yang hendak melaksanakan sholat seperti harus berwudhu', suci tempatnya karena kedua hal tersebut merupakan salah satu dari syarat shalat sehingga ketika seseorang melakukan shalat dan keduanya ditinggalkan maka hal tersebut dapat membatalkan shalat seseorang karena ketika salah syarat shahnya shalat di tinggalkan maka secara langsung shalatnya itu tidak di terima oleh Tuhan, baik itu shalat yang wajib ataupun shalat sunnah.

Shalat merupakan salah satu bentuk interaksi langsung antara manusia dengan tuhannya, maka dari itu ketika kita melakukan atau melaksanakan shalat kita di anjurkan untuk khusyuk dalam shalat yang dia lakukan supaya shalat tersebut bisa di terima oleh tuhan Yang Maha Esa, selain dari itu shalat memiliki berbagai macam keistimewaan.

\section{PEMBAHASAN}

Shalat menurut etimologi berarti doa, menurut syara' menyembah Allah Ta'ala dengan beberapa perkataan dan perbuatan yang diawali dengan takbiratul ihram dan diakhiri dengan salam.

\section{A. Shalat Fardhu}

Shalat Fardhu adalah shalat dengan status hukum fardhu, yakni wajib dilaksanakan. Shalat fardhu sendiri menurut hukumnya terdiri atas dua golongan yakni :

1. Fardhu 'Ain, yakni yang diwajibkan kepada individu. Termasuk dalam shalat ini adalah shalat lima waktu dan shalat Jumat untuk pria.

2. Fardhu Kifayah, yakni yang diwajibkan atas seluruh muslim namun akan gugur dan menjadi sunnat bila telah dilaksanakan oleh sebagian muslim yang lain. Yang termasuk dalam kategori ini adalah shalat jenazah.

Shalat lima waktu adalah shalat fardhu (salat wajib) yang dilaksanakan lima kali sehari. Hukum salat ini adalah Fardhu 'Ain, yakni wajib dilaksanakan oleh setiap Muslim atau muslimah yang telah menginjak usia dewasa (pubertas), kecuali berhalangan karena sebab tertentu.

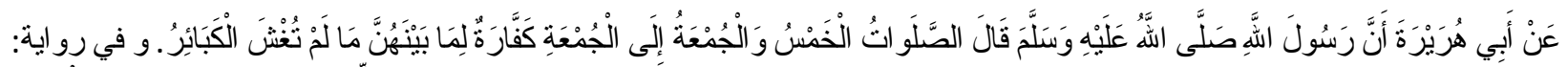

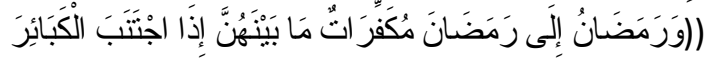

Dari Abu Hurairah RA, bahwasanya Rasulullah SAW telah bersabda, "Shalat lima waktu dan shalat Jum'at ke shalat Jum'at berikutnya menjadi pelebur dosa di antara shalat-shalat itu 
selama tidak melakukan dosa besar. Puasa Ramadhan hingga Ramadhan berikutnya menjadi pelebur dosa antara keduanya apabila meninggalkan dosa besar." \{Muslim 1/144\}

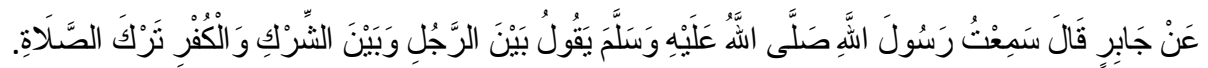

Dari Jabir RA, ia berkata, "Saya pernah mendengar Rasulullah SAW bersabda, 'Antara seorang \{muslim\} dengan syirik dan kafir adalah meninggalkan shalat.' \{Muslim 1/62\}

Shalat lima waktu merupakan salah satu dari lima Rukun Islam. Allah menurunkan perintah shalat ketika peristiwa Isra' Mi'raj. Kelima shalat lima waktu tersebut adalah:

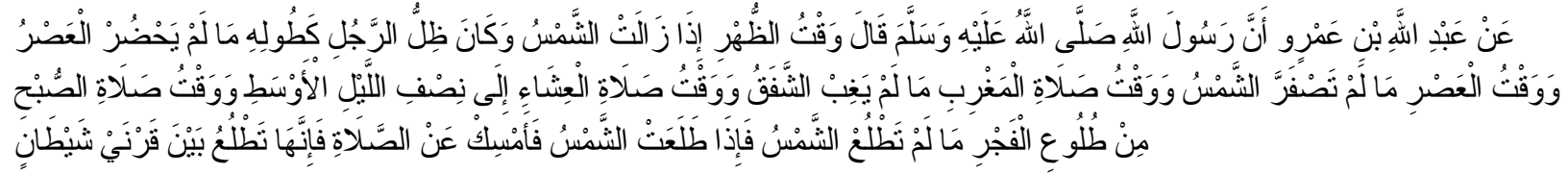

Dari Abdullah bin Amru bin Al Ash RA, bahwasanya Rasulullah SAW bersabda, "Waktu Zhuhur adalah apabila matahari telah condong sedikit ke Barat hingga bayangan seseorang menyamai panjangnya, selama waktu Ashar belum tiba. Waktu Ashar adalah selama matahari belum menguning, waktu Maghrib adalah selama mega merah belum menghilang, waktu Isya adalah hingga separuh malam yang tengah, dan waktu Shubuh adalah sejak terbit fajar sampai sebelum matahari terbit. Maka jika matahari telah terbit, janganlah kamu lakukan shalat, karena matahari terbit di antara dua tanduk syetan. \{Muslim 2/105\}

1. Subuh, terdiri dari 2 raka'at. Waktu Shubuh diawali dari terbirnya fajar, yakni cahaya putih yang melintang di ufuk timur. Waktu shubuh berakhir ketika terbitnya Matahari.

2. Zuhur, terdiri dari 4 raka'at. Waktu Zhuhur diawali jika Matahari telah tergelincir (condong) ke arah barat hingga bayangan seseorang menyamai panjangnya, dan berakhir ketika masuk waktu Ashar.

3. Asar, terdiri dari 4 raka'at. Waktu Ashar adalah selama matahari belum menguning. Waktu Ashar berakhir dengan terbenamnya Matahari.

4. Magrib, terdiri dari 3 raka'at. Waktu Maghrib adalah selama mega merah belum menghilang yang diawali dengan terbenamnya Matahari, dan berakhir dengan masuknya waktu Isya.

5. Isya, terdiri dari 4 raka'at. Waktu Isya adalah hingga separuh malam yang tengah yang diawali dengan hilangnya cahaya merah (syafaq) di langit barat, dan berakhir hingga terbitnya fajar keesokan harinya.

Khusus pada hari Jumat, Muslim laki-laki wajib melaksanakan Shalat Jumat di masjid secara berjamaah (bersama-sama) sebagai pengganti Salat Zhuhur. Shalat Jumat tidak wajib dilakukan oleh perempuan, atau bagi mereka yang sedang dalam perjalanan (musafir) 
B. Waktu shalat

Waktu shalat sangat berkaitan dengan peristiwa peredaran semu Matahari relatif terhadap bumi. Pada dasarnya, untuk menentukan waktu shalat, diperlukan letak geografis, waktu (tanggal), dan ketinggian. Urutan waktu shalat (dari pagi sampai malam) yaitu, Subuh, Zuhur, Asar, Maghrib dan Isya.

a. Zuhur

Waktu istiwa' (zawaal) terjadi ketika Matahari berada di titik tertinggi. Istiwa' juga dikenal dengan sebutan "tengah hari". Pada saat istiwa', mengerjakan ibadah salat (baik wajib maupun sunah) adalah haram. Waktu Zuhur tiba sesaat setelah istiwa', yakni ketika Matahari telah condong ke arah barat.Biasanya pada jadwal salat, waktu Zuhur adalah 5 menit setelah istiwa'.

b. Asar

Menurut mazhab Syafi'i, Maliki, dan Hambali, waktu Asar diawali jika panjang bayang-bayang benda melebihi panjang benda itu sendiri. Sementara madzab Imam Hanafi mendefinisikan waktu Asar jika panjang bayang-bayang benda dua kali melebihi panjang benda itu sendiri.

c. Magrib

Waktu Magrib diawali ketika terbenamnya Matahari. Terbenam Matahari di sini berarti seluruh "piringan" Matahari telah "masuk" di bawah horizon (cakrawala).

d. Isya dan Subuh

Waktu Isya didefinisikan dengan ketika hilangnya cahaya merah (syafaq) di langit, hingga terbitnya fajar shaddiq. Sedangkan waktu Subuh diawali ketika terbitnya fajar shaddiq, hingga sesaat sebelum terbitnya Matahari (syuruq).

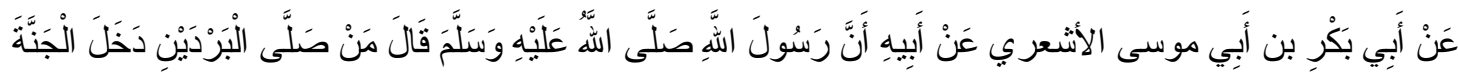

Dari Abu Bakar bin Abu Musa Al Asy'ari dari ayahnya, bahwasanya Rasulullah SAW telah bersabda, "Barang siapa melakukan dua shalat ketika dingin \{Isya dan Subuh\} maka akan masuk surga" \{Muslim 2/114\}

C. Shalat Sunah

Shalat sunah disebut juga salat an-nawâfil atau at-tatawwu'. Yang dimaksud dengan an-nawâfil ialah semua perbuatan yang tidak termasuk dalam fardhu. Disebut an-nawâfil karena amalan-amalan tersebut menjadi tambahan atas amalan-amalan shalat fardhu.

Menurut Mazhab Hanafi, shalat an-nawâfil terbagi atas 2 macam, yaitu : 
1. Shalat masnûnah ialah shalat-shalat sunah yang selalu dikerjakan Rasulullah, jarang ditinggalkan, sehingga disebut juga dengan shalat mu'akkad (dipentingkan)

2. Shalat mandûdah adalah shalat-shalat sunah yang kadang dikerjakan oleh Rasulullah, kadang-kadang juga tidak dikerjakan, sehingga disebut dengan shalat ghairu mu'akkad (kurang dipentingkan).

Salat sunah menurut hukumnya terdiri atas dua golongan yakni:

1. Muakad, adalah salat sunah yang dianjurkan dengan penekanan yang kuat (hampir mendekati wajib), seperti salat dua hari raya, salat sunah witir dan salat sunah thawaf.

2. Ghairu Muakad, adalah salat sunah yang dianjurkan tanpa penekanan yang kuat, seperti salat sunah Rawatib dan salat sunah yang sifatnya insidentil (tergantung waktu dan keadaan, seperti shalat khusuf yang hanya dikerjakan ketika terjadi gerhana).

D. Pembagian Menurut Pelaksanaan

Salat sunah ada yang dilakukan secara sendiri-sendiri (munfarid) diantaranya:
a) Shalat Wudhu
b) Shalat Tahiyyatul Masjid
c) Shalat Taubat
d) Shalat Dhuha
e) Shalat Tahajjud
f) Shalat Rawatib
g) Shalat Istikhoroh
h) Shalat Muthlaq
i) Shalat Safar

Sedangkan yang dapat dilakukan secara berjamaah antara lain:
a) Salat Tarowih
b) Shalat Dua Hari Raya
c) Shalat Gerhana
d) Shalat Istisqo'
e) Shalat Witir

E. Macam-macam shalat sunnat :

Salat sunah ada yang dilakukan secara sendiri-sendiri (munfarid) diantaranya:

a. Shalat Sunnat Wudhu' 
Shalat sunat wudhu' atau yang disebut juga dengan shalat syukrul wudhu adalah shalat yang dikerjakan setelah berwudhu'.Tata cara pelaksanaannya adalah:

1) Sehabis berwudhu kita disunahkan membaca doa:

2) Selesai membaca doa tersebut,lalu melaksanakan shalat sunah wudhu 2 rakaat.

3) Shalat ini dikerjakan 2 rakaat sebagaimana shalat yang lain dengan ikhlas sampai salam.

\section{b. Shalat Tahiyyatul Masjid}

Shalat Tahiyyatul Masjid adalah Shalat yang dilakukan sebagai penghormatan terhadap masjid, dilakukan oleh orang yang masuk ke dalam mesjid sebelum ia duduk.dikerjakan dua raka'at. Cara pengerjaannya sama dengan sholat sunat yang lainnya.

1. Shalat Taubat

Shalat Taubat adalah shalat sunnat yang dilakukan seorang muslim jika ingin bertaubat terhadap kesalahan yang pernah ia lakukan. Shalat taubat dilaksanakan dua raka'at dengan waktu yang bebas kecuali pada waktu yang diharamkan untuk melakukan shalat.

2. Shalat Dhuha

Shalat Dhuha adalah shalat sunnat yang dilakukan seorang muslim ketika matahari sedang naik. Kira-kira, ketika matahari mulai naik kurang lebih 7 hasta sejak terbitnya (kira-kira pukul tujuh pagi) hingga waktu dzuhur. Jumlah raka'at shalat dhuha bisa dengan 2,4,8 atau 12 raka'at. Dan dilakukan dalam satuan 2 raka'at sekali salam

3. Shalat Tahajud

Shalat Tahajud adalah shalat sunat yang dikerjakan pada waktu malam, dimulai selepas isya sampai menjelang subuh.

Jumlah rakaat pada shalat ini tidak terbatas, mulai dari 2 rakaat, 4, dan seterusnya.

Pembagian Keutamaan Waktu Shalat Tahajud

a) Sepertiga malam, kira-kira mulai dari jam 19.00 samapai jam 22.00

b) Sepertiga kedua, kira-kira mulai dari jam 22.00 sampai dengan jam 01.00

c) Sepertiga ketiga, kira-kira dari jam 01.00 sampai dengan masuknya waktu subuh f.Shalat Rawatib 
Shalat Rawatib adalah shalat sunah yang dikerjakan menyertai shalat fardu. Shalat sunah ini terbagi dalam shalat mu'akkad dan ghairu mu'akkad. Adapun yang termasuk dalam shalat-Shalat Sunah Rawatib adalah sebagai berikut

Mu'akkad

- Dua rakaat sebelum sholat subuh

- Dua rakaat sebelum sholat zuhur

- Dua rakaat sesudah sholat zuhur

- Dua rakaat sesudah sholat maghrib

- Dua rakaat sesudah sholat isya

\section{Ghairu Mu'akkad}

- $\quad$ Empat rakaat sebelum dan sesudah zuhur

- Empat rakaat sebelum asar

- Empat rakaat sebelum maghrib

Masing-masing berdasarkan rincian hadist-hadist berikut:

Dari Ummu Habibah: "Nabi SAW bersabda: Barangsiapa mengerjakan empat rakaat sebelum Zuhur dan empat rakaat sesudahnya maka Allah mengharamkan baginya dari api neraka." (H.R. Tirmizi).

"Dari Ibnu Umar, bahwa Nabi Muhammad SAW bersabda: Allah memberi rahmat kepada orang yang mengerjakan shalat empat rakaat sebelum shalat Asar" (H.R. Tarmizi).

Hadist Nabi Muhammad SAW: "Dari Abdullah bin Mughafal, Nabi SAW bersabda: Shalatlah kamu sebelum Maghrib, shalatlah kamu sebelum Maghrib. Kemudian Nabi mengatakan yang ketiga kalinya bagi yang menghendakinya." (H.R. Bukhari).

\section{g. Shalat Istikhoroh}

Shalat istikhoroh adalah shalat sunnah yang dikerjakan untuk memohon kepada Allah agar memberikan pilihan yang lebih baik dari dua perkara (pilihan) atau lebih untuk menghapus keraguan hati dalam memilih, agar tidak menyesal dilain hari nanti. 
Waktu mengerjakannya:

Ialah setiap saat ada kepentingan asalkan tidak waktu yang dilarang untuk mengerjakan shalat sunnah, baik siang maupun malam hari.Namun utamanya jika dikerjakan dimalam hari sebagaimana shalat tahajud, pada sepertiga malam yang terakhir.

h.Shalat Muthlaq

Shalat Muthlak adalah shalat yang dikerjakan sewaktu-waktu, kecuali pada yang dilarang untuk mengerjakan shalat sunnat, misalnya sesudah shalat subuh dan shalat ashar.

Waktu-waktu yang dilarang dalam mengerjakan shalat mutlak:

(a) Disaat matahari akan terbit sampai naik sepenggalah (setinggi tombak).

(b) Disaat matahari berada ditengah-tengah persis sampai tergelincir kebarat (lingsir).

(c) Disaat matahari akan terbenam sampai terbenam secara sempurna (tiba waktu maghrib).

(d) Setelah shalat ashar sampai matahari terbenam.

(e) Setelah shalat subuh sampai matahari naik sepenggalah (setinggi tombak).

\section{i.Shalat Safar}

Apabila seseorang hendak berpergian, sebelum meninggalkan rumah, ia dianjurkan mengerjakan solat safar dua rakaat; demikian pula sesudah tiba di rumah kembali.

Caranya sama dengan mengerjakan solat subuh, hanya niatnya berlainan, yaitu berniat solat safar sunnat karena Allah SWT. Selesai solat berdoalah agar perjalanan diridhai, dimudahkan dan diselamatkan Allah SWT. dalam perjalanan, baik pribadi, tugas maupun keluarga yang ditinggalkan.

Sedangkan yang dapat dilakukan secara berjamaah antara lain:

\section{a.Shalat Tarowih}

Shalat tarowih adalah shalat sunnat yang dikerjakan pada malam bulan ramadhan. Waktu shalat tarowih ialah sesudah shalat isya' sampai terbit fajar (masuk waktu subuh).

b. Shalat Dua Hari Raya

Sholat hari raya adalah shalat sunnat yang dikerjakan pada kedua hari raya, yaitu: hari raya Fitri (tgl. 1 Syawal) dan hari raya Adlha (kurban tgl. 10 Dzul Hijjah).

Cara mengerjakannya : 
1. Waktu shalat hari raya fitri itu, pada tanggal 1 syawal mulai terbit matahari sampai matahari tergelincir (datang waktu dhuhur).

2. Dan shalat hari raya kurban, pada tanggal 10 djul hijjah (bulan haji) mulai terbir matahari sampai matahari tergelincir (tiba waktu dhuhur).

c.Shalat Dua Gerhana

Shalat dua gerhana adalah shalat yang dikerjakan karena ada gerhana bulan dan matahari.

Cara mengerjakannya :

Cara mengerjakan shalat dua gerhana itu boleh dikerjakan secara sendirian, tetapi utamanya dikerjakan secara berjama'ah.

d. Shalat Istisqo'

Shalat istisqo'adalah shalat sunnat yang dikerjakan, karena ada keperluan untuk mohon hujan.

e.Shalat Witir

Shalat witir adalah shalat yang dikerjakan dengan bilangan ganjil. Misalnya : satu raka'at tiga, lima dan seterusnya.Waktunya setelah shalat shalat isya' sampai terbit fajar (tiba waktu subuh).

Rasulullah s.a.w bersabda :“Ij’aluu akhirosholaatikum bil laili witron.”

Artinya :"Jadikanlah akhir shalatmu pada waktu malam dengan witir."

(HR.Bukhori dan Muslim yang bersumber dari Ibnu 'Umar r.a.). 


\section{PENUTUP}

\section{A. Kesimpulan}

Shalat merupakan rukun Islam yang kedua setelah dua kalimat syahadat. Shalat terbagi 2 yaitu Shalat Fardhu dan Shalat Sunnat. Shalat Fardhu hukumnya wajib dan mencegah seseorang dari perbuatan keji dan mungkar. Shalat yang bagaimanakah yang dapat mencegah seseoarang dari perbuatan keji dan mungkar? Yaitu shalat yang dilakukan dengan hati yang ikhlas serta khusyu' dalam pelaksanaannya. Dengan shalat dapat membentuk pribadi yang mempunyai sifat tawadhu', pandai bersyukur, slalu tawakal, sabar, tabah dalam mengarungi kehidupan. Membina muslim agar senantiasa hidup bersih dan suci jiwa dan raga. Shalat merupakan sarana untuk menyampaikan pernyataan diri manusia kepada Tuhan-Nya secara tulus ikhlas bahwa semua yang ada pada dirinya, shalat dan ibadahnya, hidup dan matinya hanya milik Allah.

Shalat fardu hukumyan wajib artinya jika dikerjakan berpahala, jika ditinggalkan berdosa. Shalat fardu terbagi atas 5 waktu, yaitu :

1. Subuh

2. Dzuhur

3. Ashar

4. Maghrib

5. Isya 